\title{
Comunicação
}

[Communication]

\section{Situação epidemiológica da leucose bovina enzoótica em Portugal entre os anos de 1995 e 2005}

[Epidemiological survey of enzootic bovine leukosis in Portugal from 1995 to 2005]

\author{
P. Poeta ${ }^{1,2}$, A.C. Coelho ${ }^{1,2}$, J. Rodrigues ${ }^{1,2}$ \\ ${ }^{1}$ Departamento de Ciências Veterinárias \\ Universidade de Trás-os-Montes e Alto Douro \\ Quinta de Prados \\ 5000-911 - Vila Real, Portugal \\ ${ }^{2}$ Centro de Estudos de Ciências Animais e Veterinárias - CECAV - Vila Real, Portugal
}

\begin{abstract}
A leucose bovina enzoótica (LBE) é uma doença de declaração obrigatória (OIE, 2005) que, em Portugal, é reforçada pelo DL n. ${ }^{\circ} 114 / 99$ de 14 de abril (Portugal, 1999; Boletim..., 2004). A erradicação é considerada uma prioridade. O plano de erradicação, apresentado pela primeira vez à Comissão Européia (CE) em 1987, foi aprovado pela Decisão da Comissão n. ${ }^{\circ}$ 88/209/CEE de 28 de fevereiro de 1988, com validade de um período de três anos. Desde então, as ações de luta contra a LBE foram efetuadas em regime de voluntariado e, de novembro de 1995 a dezembro de 1996, realizou-se uma avaliação da situação epidemiológica mediante levantamento da incidência da doença, cujos resultados levaram Portugal a submeter à aprovação da CE, em 1999, um plano de erradicação, que foi aprovado pela Decisão da Comissão $n^{0}$ 98/703/CEE de 26 de novembro de 1998. Este programa tem estado a decorrer desde 1999 (OIE, 2005). Foram submetidos planos entre 2000 e 2003, o último aprovado pela Decisão 943/2002/CE de 28 de novembro de 2002. Posteriormente, apresentou-se um plano de erradicação para 2005, com vista a continuar as ações em curso (Boletim..., 2004).
\end{abstract}

O objetivo do presente trabalho foi o de apresentar um levantamento da situação da leucose bovina enzoótica, em Portugal, entre os anos de 1995 e 2005.

Os dados sobre leucose bovina enzoótica foram oficialmente obtidos por meio do registro de

Recebido em 14 de março de 2008

Aceito em 2 de setembro de 2008

E-mail: ppoeta@utad.pt
Direção Geral de Veterinária (Boletim..., 2003, 2004; Dados..., 2006), entidade controladora da doença em Portugal. Foram considerados como critérios de inclusão todos os bovinos saneados durante a campanha de erradicação da doença entre os anos de 1995-2005, realizada pelas Organizações de Produtores Pecuários (OPP) sob tutela da Direção Geral de Veterinária. $O$ animal foi considerado como positivo quando reagiu ao teste sorológico oficial.

O teste utilizado, imunodifusão em gel de ágar (IDGA), está de acordo com a legislação comunitária sobre a matéria, nomeadamente a Diretiva do Conselho $n^{\circ}$ 97/12/CE de 17 de março (Boletim..., 2004). De acordo com o plano de erradicação (Portugal, 1999; Programa..., 2005), todos os bovinos com mais de 24 meses foram submetidos ao controle sorológico, uma vez por ano. Nas explorações infectadas, todos os animais com mais de 12 meses foram submetidos a testes sorológicos, com intervalos entre três a seis meses, após o abate do último animal positivo, até se obterem resultados negativos. Nas explorações suspeitas, todos com mais de um ano foram submetidos à sorologia, com intervalo entre seis a 12 meses (Boletim..., 2003).

Sempre que a prevalência da doença ultrapassou os $5 \%$ dos animais reprodutores, procedeu-se ao isolamento e ao abate dos animais infectados e suspeitos de infecção desde que as razões de natureza epidemiológica o justificassem (Boletim..., 2004). 
Estes foram alvo de abate sanitário com inspeção post-mortem da carcaça para a pesquisa de achados de matadouro compatíveis com a doença. Calcularam-se a prevalência individual da enfermidade e a prevalência por explorações quando, no mínimo, apareceu um animal positivo. A incidência foi calculada como o número de novas explorações infectadas sobre o total de explorações indenes no ano anterior.

As variáveis dependentes estudadas foram: ano epidemiológico; Direção Regional de Agricultura (DRA), que corresponde à localização da exploração ou área; e aptidão dos animais. As variáveis foram codificadas, digitadas e analisadas pelo programa SPSS $10.0 \AA$.

Os dados referentes à Direção Regional de Agricultura dos Açores foram, durante o estudo, sempre referidos de forma independente, visto que, para a Região Autônoma dos Açores, foi apresentado um programa específico devido ao fato de essa área ser um arquipélago português, situado a algumas milhas da costa continental e, como tal, funcionar como uma unidade epidemiológica distinta (Boletim..., 2004).

Durante o período de 1995 a 2005, foram abatidos 26.922 bovinos. O maior número de abates ocorreu em 1996 e 2000 . Cerca de $50 \%$ do total de abates reportam-se aos anos entre 1999 e 2002. A Fig. 1 ilustra a percentagem de bovinos positivos em Portugal Continental entre 1995 e 2005 . Apesar das oscilações, entre 1995 e 2005 houve diminuição acentuada da percentagem de soropositivos. Em 1995, foi registrado o maior número de animais soropositivos (1,7\%). Em 1995 e 1996, ocorreu ligeira redução da prevalência, que voltou a aumentar em 1997. As medidas aplicadas para a erradicação da doença resultaram em redução drástica no ano de 1998, voltando, contudo, a aumentar em 1999. De 2000 a 2001, novamente, ocorreu diminuição seguida de aumento, em 2002. A partir desse ano, a doença apresentou diminuição da prevalência, sendo a do ano de 2005 a de valor mais baixo. De 1995 a 2005, observou-se decréscimo nos valores da prevalência.

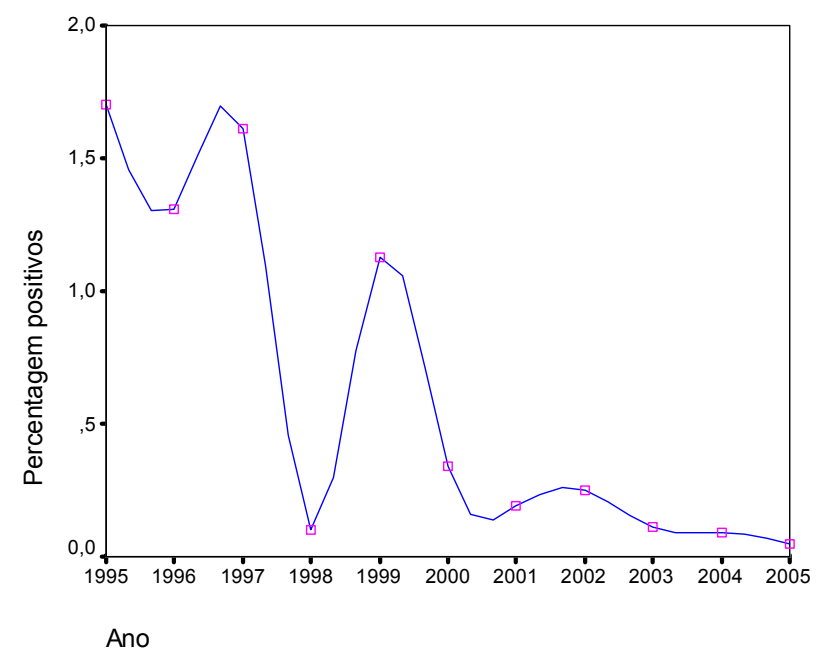

Figura 1. Distribuição da percentagem de bovinos positivos para leucose bovina enzoótica em Portugal Continental durante o período de 1995 a 2005 (Fonte: Dados..., 2006).

No Continente, ocorreu aumento de casos novos de leucose bovina enzoótica entre 2003 e 2004, seguido de diminuição em 2005. Relativamente aos Açores, verificou-se, no mesmo período, descida acentuada da incidência da doença até atingir o valor de zero, em 2005. No total nacional, os valores da incidência estabilizaramse entre 2003 e 2004, diminuindo quase para metade em 2005 (Fig. 2)
De 1995 a 2005, foram detectados 25.003 casos da doença. A Fig. 3 apresenta a distribuição do número de casos da doença pelas diferentes DRA. À exceção do Algarve, a infecção distribuiu-se de norte a sul, sendo mais esporádica nos Açores. O maior número de explorações e casos positivos ocorreu na DRA de Trás-os-Montes, seguindo-se as de Entre Douro e Minho e Ribatejo e Oeste. 


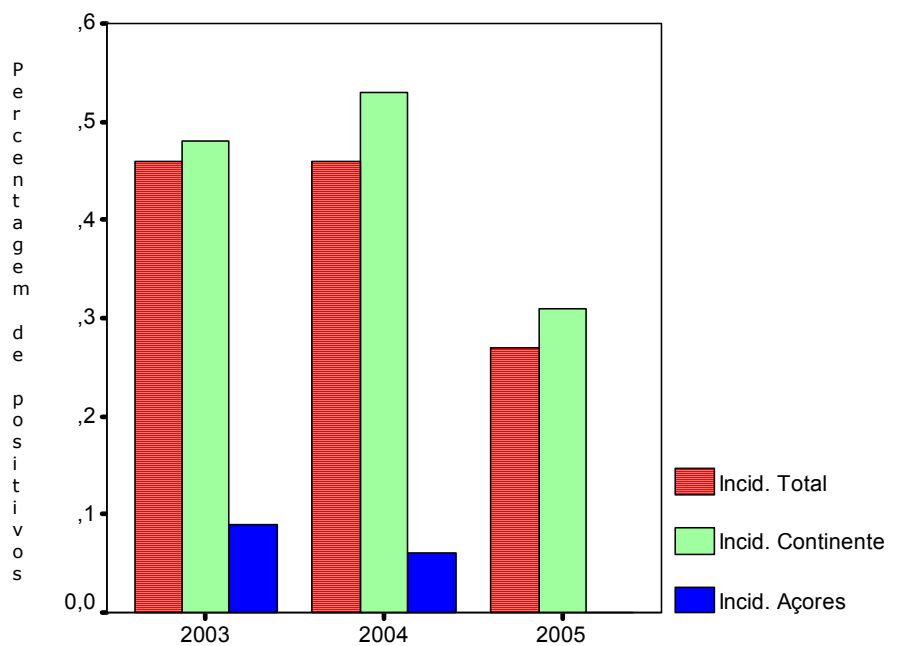

Figura 2. Incidência da leucose bovina enzoótica em Portugal durante o período de 2003 a 2005 (Incid.: Incidência) (Fonte: Dados..., 2006).

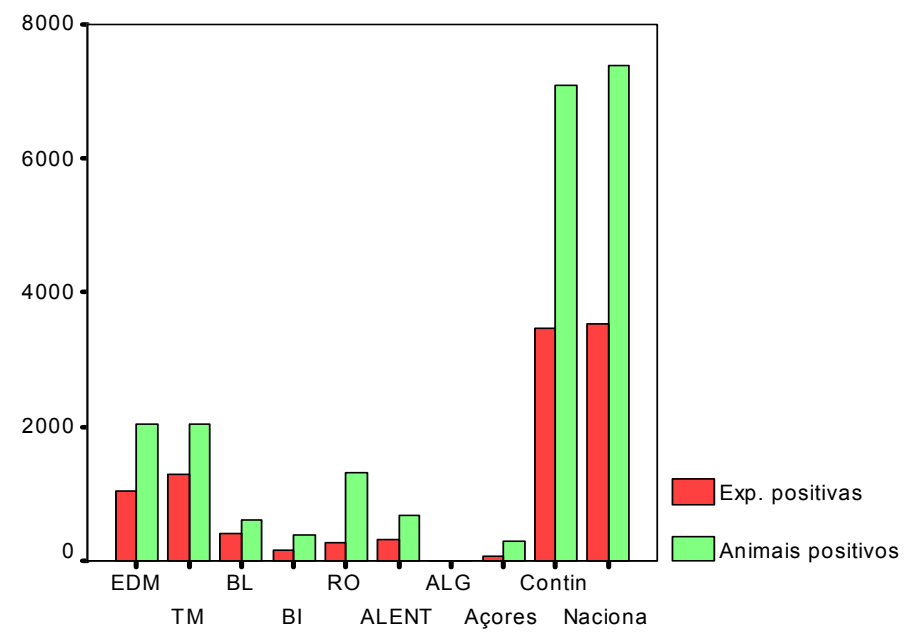

Figura 3. Distribuição do número de explorações e bovinos positivos para leucose bovina enzoótica em Portugal entre 1995 e 2005 (Fonte: Dados..., 2006).

EDM: Entre Douro e Minho; TM: Trás-os-Montes; BL: Beira Litoral; BI: Beira Interior; RO: Ribatejo e Oeste; ALENT: Alentejo; ALG: Algarve; Contin: Continente; Naciona: nacional.

As Tab. 1 e 2, relativas ao ano de 2005, sintetizam os resultados do plano de erradicação, considerando-se o número de explorações e o número de bovinos, respectivamente, quer no Continente quer na Região Autônoma dos Açores. Relativamente às explorações, existiam 70.756 efetivos bovinos no Continente, tendo sido controladas 47.085, com $0,37 \%$ de explorações infectadas. As DRA de Trás-osMontes e Entre Douro e Minho foram as que registraram maior percentagem de explorações infectadas. Nos Açores, existiam 12.437 explorações, das quais 7596 foram rastreadas com $0,07 \%$ das explorações infectadas (Tab. 1).

Em 2005, existiam 1.080.204 bovinos no Continente, dos quais 663.044 foram sujeitos a controle. Foram as DRA de Entre Douro e Minho (190) e de Trás-os-Montes que tiveram o maior número de animais positivos (46) e de abatidos (253 e 93, respectivamente). Nos Açores, o efetivo foi de 270.366, com 128.285 animais rastreados, dos quais 11 foram positivos $(0,01 \%)$ (Tab. 2). 
Situação epidemiológica da leucose...

Tabela 1. Leucose bovina enzoótica em 2005 nas diferentes regiões de Portugal (explorações) (Fonte: Dados..., 2006)

\begin{tabular}{|l|l|l|l|l|}
\hline Regiões de Portugal & $\begin{array}{l}\text { Explorações } \\
\text { Existentes }\end{array}$ & $\begin{array}{l}\text { Explorações } \\
\text { Controladas }\end{array}$ & $\begin{array}{l}\text { Explorações } \\
\text { Positivas }\end{array}$ & $\begin{array}{l}\text { \% Explorações } \\
\text { Positivas }\end{array}$ \\
\hline Entre Douro e Minho & 30045 & 19690 & 86 & 0,44 \\
\hline Trás-os-Montes & 7212 & 6451 & 34 & 0,53 \\
\hline Beira Litoral & 18347 & 11305 & 24 & 0,21 \\
\hline Beira Interior & 3835 & 2907 & 8 & 0,28 \\
\hline Ribatejo e Oeste & 5471 & 1688 & 5 & 0,30 \\
\hline Alentejo & 5255 & 4521 & 18 & 0,40 \\
\hline Algarve & 591 & 523 & 0 & 0,00 \\
\hline Total Continente & 70756 & 47085 & 175 & 0,37 \\
\hline Açores & 12437 & 7596 & 5 & 0,07 \\
\hline Total Nacional & 83193 & 54681 & 180 & 0,33 \\
\hline
\end{tabular}

Tabela 2. Leucose bovina enzoótica em 2005 nas diferentes regiões de Portugal (animais) (Fonte: Dados..., 2006)

\begin{tabular}{|l|l|l|l|l|}
\hline Regiões de Portugal & $\begin{array}{l}\text { Bovinos } \\
\text { Existentes }\end{array}$ & $\begin{array}{l}\text { Bovinos } \\
\text { Controlados }\end{array}$ & $\begin{array}{l}\text { Bovinos } \\
\text { Positivos }\end{array}$ & $\begin{array}{l}\% \text { Bovinos } \\
\text { Positivos }\end{array}$ \\
\hline Entre Douro e Minho & 264426 & 146081 & 190 & 0,13 \\
\hline Trás-os-Montes & 62364 & 40951 & 46 & 0,11 \\
\hline Beira Litoral & 132684 & 66107 & 39 & 0,06 \\
\hline Beira Interior & 55474 & 33811 & 9 & 0,03 \\
\hline Ribatejo e Oeste & 189619 & 66494 & 5 & 0,01 \\
\hline Alentejo & 367136 & 304014 & 25 & 0,01 \\
\hline Algarve & 8501 & 5586 & 0 & 0,00 \\
\hline Total Continente & 1080204 & 663044 & 314 & 0,05 \\
\hline Açores & 270366 & 128285 & 11 & 0,01 \\
\hline Total Nacional & 1350570 & 791329 & 325 & 0,04 \\
\hline
\end{tabular}

Na região norte do país onde existe o maior número de explorações leiteiras, os resultados assemelham-se aos de outros autores (Ferrer, 1979; Megid et al., 2003), ou seja, é na criação de bovinos de leite que se concentra o maior número de animais infectados. Esse fato, provavelmente, reflete a criação de forma intensiva ou semi-intensiva, pois os animais estão sujeitos a situações que favorecem a transmissão da doença.
Os resultados sugerem que o país registrou um importante decréscimo nos valores da prevalência e incidência da doença durante $\mathrm{o}$ período do estudo.

Palavras-chave: leucose bovina, epidemiologia, Portugal 


\begin{abstract}
This paper evaluated the epidemiological situation of the enzootic bovine leucosis from 1995 to 2005, in Portugal. With exception of the South region, Algarve, the disease was distributed throughout the country, being more prevalent in the north, between Douro and Minho and Trás-os-Montes, than in the centre. A decrease in prevalence and incidence of the infection throughout the studied period was also observed.
\end{abstract}

Keywords: bovine leukosis, epidemiology, Portugal

\section{AGRADECIMENTOS}

Os autores agradecem à Dra. Ana Paula Figueiras e à Dra Adosinda Coelho, da Direção Regional de Agricultura de Trás-os-Montes, e à Direção Geral de Veterinária, por todo apoio e colaboração neste trabalho.

\section{REFERÊNCIAS BIBLIOGRÁFICAS}

BOLETIM Zoo-Sanitário. Lisboa: Direção Geral de Veterinária, 2003

BOLETIM Zoo-Sanitário. Lisboa: Direção Geral de Veterinária, 2004

PROGRAMA de erradicação da leucose bovina enzoótica. Lisboa: Direção Geral de Veterinária, 2005.

DADOS sobre a leucose bovina enzoótica referentes a 2004 e 2005. Lisboa: Direção Geral de Veterinária, 2006 (Ofício de 354 de 28 de fevereiro 2006).

FERRER, J.F. Bovine leukosis: natural transmission and principles of control. J. Am. Vet. Med. Assoc., v.175, p.1281-1286, 1979.

MEGID, J.; NOZAKI, C.N.; KURODA, R.B.S. Ocorrência de leucose enzoótica bovina na microrregião da Serra de Botucatu. Arq. Bras. Med. Vet. Zootec., v.55, p.645-646, 2003.

OIE. Código Sanitário para los Animales Terrestres. Disponível em: <http://www.oie.int/esp/normes/mcode/ E_summry.htm>. Acessado em: 21 jan. 2005.

PORTUGAL. Ministério da Agricultura, do Desenvolvimento Rural e das Pescas Decreto-Lei n. ${ }^{\circ}$ 114/1999, de 14 de Abril de 1999. Lisboa: Diário da República, I Série-A, nº 87, 1999. 